\section{Knife-edge of design}

\section{Jack Cohen}

$\mathrm{V}$ ictorian biologists were fond of the phrase "The profligacy of nature". As biology lost its contact with natural history and took up with Mendel and Fisher in the early 1900s, this profligacy — which had so impressed Darwin and Wallace - was replaced by Latin squares and normal distributions. The bean-counters had forgotten nature. We have to remind biology students today that two parents produce only two parents: about 14 of every 16 starlings die without breeding, a female frog lays about 10,000 eggs, of which about two breed, and all but about two of 40 million cod eggs contribute to food chains, and not to the future of their species. Many of us had forgotten this by the 1960s. John W. Saunders, in his excellent 1970 book on embryology, wrote: "Almost without fail each egg produced in the right environment does form a new individual that in turn makes sperm or eggs that begin another generation."

Reproductive biology has changed again since then. We used to believe, like Saunders, that reproduction is basically replication with few mistakes. We now realize that even bacterial replication generates many mistakes, requiring a whole suite of enzymes to repair them - a process that does not usually recover the original sequence.

I would date the beginning of the change to the discovery of $\mathrm{p} 53$, the 'cell-suicide' protein. Before that, examples of programmed cell death (apoptosis) in our embryology teaching were surprising exceptions. After p53 was discovered, the apoptosis bandwagon led to detailed investigation of branching apoptotic mechanisms, regulation of developmental cell numbers, mutation control,

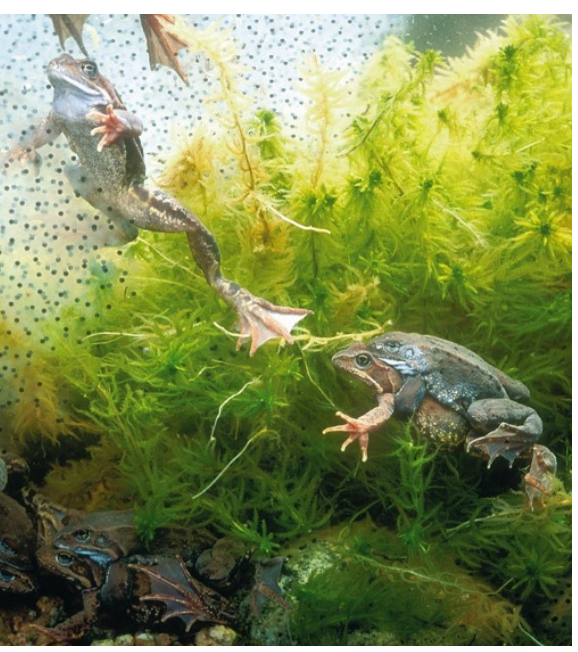

Spawn free: but only a tiny fraction will survive. recognition of DNA double-strand breaks, and recognition and repair of other DNA problems. Caspases and anti-caspases, the main enzymes involved, became part of cell biologists' picture of the eukaryotic cell. Rather than the cyclical, balanced machinery of the old biochemical-pathway charts, the metazoan cell came to be seen as tottering on a knife-edge between physiology and pathology. Normal physiology is not so much buffered as machine-gunned if it strays from the narrow path. Cell death is normal.

Two other revelations confronted our earlier prejudices. First, prokaryotes have 'trainwrecks' in at least a third of their replications, so a functional genome requires gene conversion and other nucleotide-replacement mechanisms. This has pushed Escherichia coli off its pedestal as the classical example of simple replication. We had thought that gene-conversion and chromosome-crossover mechanisms were invented by eukaryotes for the business of squeezing mendelism out of meiosis. We now see that they are rooted in the repair of ancient prokaryote (archaean) mistakes. Second, mammalian spermatozoa have far too many double-strand breaks to contemplate human reproductive technologies such as intra-cytoplasmic sperm insertion without some concern. Woody Allen was wrong - most spermatozoa are cripples.

The 'few mutated mendelian alleles' population-genetics models of Fisher and Haldane should have been replaced by the 'recombination of very many alleles' Lewontin school in the 1960s or 1970s, when wild populations were found to carry too many genetic variants for the former. Kimura's proposal that most of the variety is 'neutral' delayed this. But measurements of wild populations of eels in eastern US rivers (elvers are much more varied than adults), for example, show that breeding organisms are usually a tiny fraction of the recombinational possibilities, regenerating the variety in their offspring. Haldane believed that loss of one-third of a population, as mutant alleles came in or were lost, would be disastrous. We now realize that 1 in 1,000 breeders is normal, and 1 in 1,000,000 is not unusual.

Sperm numbers illustrate the point well. In ascomycete fungi we can see all the products of each meiotic event: effectively, both DNA strands of the 'gamete' level are expressed in the eight ascospores. We can see that they get about a third of the products of each crossover 'wrong' in gene conversions. If metazoan crossovers do the same thing, and if these gene conversions render gametes redundant, this would exactly account for the huge numbers of sperm produced. Only a few sperm can normally reach the site of

\section{Reproductive wastage}

"Now that we have information about the genetic ecology of wild populations, and we can see how far from nature Mendel, Fisher and Haldane were, it is time to grasp the complexity of real life."

fertilization, the vast majority being labelled and phagocytosed - a conclusion that has only recently been generally accepted.

This arresting reversal of our paradigm of biological reproduction seems not yet to have been generally noticed. University population-genetics courses are still wedded to mendelian peas and laboratory Drosophila models, and most modern evolutionary and population-genetic models are grounded in few-mutant-allele thinking, often with a neutralist viewpoint. Now that we have information about the genetic ecology of wild populations, and we can see how far from nature Mendel, Fisher and Haldane were, it is time to grasp the complexity of real life instead of using easy arithmetic and fairy stories to describe how reproduction works.

Perhaps this proneness to mistakes in reproduction is evidence that well-designed, efficient biology is out of reach of the natural selection of undirected genetic change. We could go further and claim that terrestrial life has achieved only barely enough effective multiplication to keep biology going.

My preferred alternative is to see such variety as exuberantly exploiting any ecological possibility with a new life-form. Rather than regarding all the plaice larvae that fail to become breeders as 'waste', I wonder at the variety of successful species of flatfish, from dabs to halibut, all derived from twisted, aberrant teleosts that have adapted to lying on one side and warping their skull bones to bring the lower eye onto the top. If life had not been so prodigal, Paley might not have been so impressed by its appearance of design.

Jack Cohen is in the Mathematics Institute, University of Warwick, Coventry CV4 7AL, UK.

\section{FURTHER READING}

Sakkas, D. et al. Origin of DNA damage in ejaculated human spermatozoa. Reviews of Reproduction 4, 31-37 (1999).

Ninio, J. Illusory defects and mismatches: why must DNA repair always be (slightly) error-prone? BioEssays 22, 396-401 (2000).

Cox, M. M. et al. The importance of repairing stalled replication forks. Nature 404, 37-41 (2000).

Cohen, J. Sperms galore: why mammals produce huge numbers of spermatozoa. Science Spectra 16, 14-20 (1999). 